\title{
CLEFT LIP AND/OR CLEFT PALATE AS COEXISTING DEFECTS IN SELECTED RARE DISEASES, WITH EMPHASIS ON DENTAL ABNORMALITIES AND SPEECH PROBLEMS: A NARRATIVE REVIEW OF THE LITERATURE
}

\author{
Agata Żółtowska' (DD, Agnieszka Kamyk-Wawryszuk² (DD, Katarzyna Machut' ${ }^{1}$, Katarzyna Ziajka³ \\ 'Department of Endodontic Dentistry, Faculty of Medicine, Medical University of Gdańsk, Poland \\ ${ }^{2}$ Department of Special Education and Speech Therapy, Kazimierz Wielki University, Bydgoszcz, Poland \\ ${ }^{3}$ Department of Anesthesiology and Intensive Care, Specialist Hospital Ludwik Rydygier in Kraków, Poland
}

\begin{abstract}
INTRODUCTION: Nowadays, 600 genetic syndromes are known with reported cleft palate or cleft lip, however, the etiology is not exactly known.

ОвJеCтIVES: This paper aims to review the medical literature to present the issue of cleft lip and cleft palate in selected rare diseases. The above-mentioned syndromes are due to extremely complex and heterogeneous etiology. MATERIAL AND METHODS: Using hand and electronic methods, the literature was searched for original papers, case studies, review papers, epidemiological databases, and book chapters, which focused on cleft lip and/or cleft palate and rare diseases. Publications were dated from 1999 to 2019. The majority of articles were in English, except some Polish papers. Key terms used in the search included speech therapy, dental manifestation, rare diseases, Hay-Wells syndrome, Smith-Lemli-Opitz syndrome, diastrophic dysplasia, Apert syndrome, and Kabuki syndrome. There were 49 references in total.

RESULTS: Cleft palate and cleft lip are not the most common birth defects in human population, but are probably the most complicated conditions, which require an interdisciplinary approach of specialists from numerous medical fields. If a cleft palate occurs, patients are more likely to be exposed to rejection and non-acceptance by society.

ConcLusions: This narrative review provides a description of five rare genetic diseases associated with cleft palate and/or cleft lip, with an emphasis on orofacial symptoms. Cleft palate and cleft lip conditions affect patients' quality of life and require multidisciplinary treatment.
\end{abstract}

KEY WORDS: speech therapy, rare diseases, dental manifestation, palate abnormalities.

J Stoma 2021; 74, 4: 267-272

DOI: https://doi.org/10.5114/jos.2021.111290

\section{INTRODUCTION}

Cleft lip and/or palate (CLP) is the most common congenital malformations of the facial skeleton. The prevalence of this syndrome is 1-7 per 1,000 live newborns [1], and represent $14-17 \%$ of all malformations. The frequency of this defect depends on race, region, socio-economic conditions as well as methods' of research. The most common cleft palates occur in the Asian population, resulting in 0.79-3.74 per 1,000 live births (Indians
JOURNAL OF STOMATOLOGY CZASOPISMO STOMATOLOGICZNE
ADDRESS FOR CORRESPONDENCE: Katarzyna Machut, Department of Endodontic Dentistry, Faculty of Medicine, Medical University of Gdańsk, 18 E. Orzeszkowej St., 80-208, Gdańsk, Poland, phone: + 48511762 339, e-mail: kasia.machut@gmail.com RECEIVED: 26.06.2021 • ACCEPTED: 16.08.2021 • PUBLISHED: 05.12.2021 
3.6/1,000, Japanese 2.1/1,000, Chinese 1.7/1,000). In contrast, the lowest percentage of these defects occurs among Afro-Americans, ranging from 0.18 to 1.67 per 1,000 live births. Among Caucasians, the average incidence of CLP is about 0.91-2.69 per 1,000 live births, while in Europe, they are quite common in Sweden $(2 / 1,000)$ and Denmark $(1.9 / 1,000)$ [2-6].

CLP is caused by an influence of genetic factors (e.g., chromosome aberrations, single-gene mutations, multiple genetic factors), environmental factors, or both. According to the literature, the impact of environmental factors in cleft etiology is only rated at $10 \%$ [7].

Patients with cleft palates demonstrate multiple problems, such as early feeding difficulties, nutritional problems, developmental delays, abnormal speech and/ or nasal resonance, dentofacial and malocclusions, hearing loss, and psychosocial issues [7, 8]. Visible facial deformities, usually audible speech defects and dental disorders, often affect personal life and social functioning of patients with cleft palate and/or lip $[9,10]$.

Rapid growth of the maxillary process occurs between $5^{\text {th }}$ and $6^{\text {th }}$ week of fetal life. By the $7^{\text {th }}$ week, the maxillary, and medial and lateral nasal processes are integrated to form intermaxillary segment. As a result, the upper lip and the maxilla (front of the maxilla to incisive foramen) are formed, called the primary palate. Cleft lip develops due to improper proliferation of the maxillary and medial nasal processes $[11,12]$.

The secondary palate consists of hard and soft palate. It develops during $7^{\text {th }}$ to $12^{\text {th }}$ week of embryogenesis. Palatal shelves derive from the medial surface of the maxillary processes by $6-7^{\text {th }}$ week of fetal life. At first, that shelves grow medially and then, vertically down. Final fusion ensues at $10-12^{\text {th }}$ week of intrauterine life. That usually occurs with a delay in males rather than females. Failure of fusion of both sides' maxillary shelves and with frontonasal processes, lead to cleft palate $[11,12]$.

Cleft palate can be divided into an incomplete cleft of secondary palate, complete cleft of secondary palate, unilateral complete cleft of primary and secondary palate, and bilateral complete cleft of primary and secondary palate [8]. Abnormalities in oronasal and orofacial structure, delayed growth, acquired neuromotor patterns during early infancy, and/or disturbed psychosocial development, are all observed to be the causes of most speech problems among individuals with cleft palates. The interference of misaligned teeth, residual clefts, and fistulas, are considered as the causes of speech fallacies. Unless the underlying structural deformity is repaired, these errors could not be corrected by speech therapy. Speaking errors, which can be corrected by a therapy, are those adaptive articulation skills, learned by children during their development $[13,14]$.

Noor et al. reported that as much as $75 \%$ of patients with a cleft has been the object of unpleasant remarks from colleagues [15]. Hunt et al. showed that teasing (not the fact of cleft) might be a determinant of bad mental condition of people with this defect $[10,16]$. Topolski et al. and Oosterkamp et al. emphasized the relationship between facial appearance and psychosocial functioning $[17,18]$. Therefore, it was indicated to include psychological support into the treatment [19]. Geneser et al. reported that children born with cleft lip and/or palate experience a few medical problems, and they require care from medical teams involving many specialists. In their opinion, pedodontists and orthodontists play an important role in this interdisciplinary work, because they not only provide dental treatment but often coordinate many aspects of whole therapy [8].

This review presents five rare congenital disorders, which were randomly selected, based on authors' clinical and research experiences. These syndromes are autosomally inherited in a dominant or a recessive pattern. Furthermore, all of the represented diseases are associated with cleft palate and/ or lip. Mainly, we have focused on cleft palate and/or lip, with additional craniofacial anomalies and their potential impact on patient's speech. The main clinical implication of these studies is to popularize complex problem of rare diseases, highlighting craniofacial deformities and difficulties, which have a direct impact on the quality of life of patients.

Narrative overview of the literature was performed, synthesizing the findings retrieved from searches of computerized databases (Mendeley, PubMed, ResearchGate, ScienceDirect) and hand searches, including original papers, case studies, review papers, epidemiological databases, and book chapters, focusing on cleft lip/palate and rare diseases. Publications dated from 1999 to 2019 were considered. The majority of articles were in English, with a few Polish articles taken into consideration during the preparation of this paper. In total, 49 references were used to prepare the review. Key terms used in the search included speech therapy, dental manifestation, rare diseases, Hay-Wells syndrome, Smith-LemliOpitz syndrome, diastrophic dysplasia, Apert syndrome, and Kabuki syndrome.

\section{HAY-WELLS SYNDROME}

Hay-Wells syndrome (HWS), also known as ankyloblepharon-ectodermal defects lip/palate (AEC) syndrome, is one of over one-hundred forms of ectodermal dysplasia. HWS syndrome present autosomal dominant inheritance pattern. This disorder affect tissue groups that arise from the ectoderm (outer layer of the embryo), which undergo abnormal development. The most relevant abnormalities of HWS are a partial fusion of the edges of the eyelids (ankyloblepharon filiforme adnatum), ectodermal disorders, and cleft lip and/or palate. This syndrome is rarely described in the literature and the prevalence rate is unknown. Isolated cases of AEC syndrome with an additional feature as bilateral 
choanal atresia were previously described by Hay-Wells and Bertola [20].

The syndrome is caused by a missense mutation of TP63 gene, locus 3q28, which is encoded as a protein p63 [21]. As a transcription factor, it is responsible for the correct fusion of individual DNA regions and for controlling the activity of specific genes [20].

Apart from ankyloblepharon and cleft lip and/or palate, there are other features of HWS, such as hypertrichosis, slight hypohidrosis, recurrent otitis media, scalp/skin erosions, nails abnormalities (thin, distorted, or absent), hypodontia, and maxillary hypoplasia [22].

The clinical variant of Hay-Wells syndrome with the same etiology is curly hair-ankyloblepharon-nail disease (CHAND) syndrome [23]. Usually, diagnosis is based on clinical features. Hair microscopy and genetic tests are helpful in further diagnosis. Light microscopy and scanning electron microscopy of hair from patients with AEC syndrome showed many changes, including flattening, triangular shape, longitudinal deep or shallow grooves, and irregular surface indentations. Also, variable pigmentation from pallidness to absence of pigment can be observed [20,24].

The vast majority (nearly $80 \%$ ) of patients with HayWells syndrome are identified with cleft primary and/or secondary palate [20]. Only some authors have reported a possibility of delayed speech development. The specificity of speech disorders in this syndrome has not been described yet, and the need for speech therapy was occasionally emphasized [25].

\section{KABUKI SYNDROME}

Kabuki syndrome (Niikawa-Kuroki syndrome) is a rare disorder that is characterized by facial dysmorphism, minor skeletal defects, fetal pads in the fingers, intellectual disabilities of varying degrees, and post-birth growth deficiency. Kabuki syndrome is a pan-ethnic condition. In Japanese population, the incidence of Kabuki syndrome is estimated to be 1 in 32,000 live births. In other populations, the syndrome is considered to occur with a similar prevalence [26]. In contrast, in Australia and New Zealand, the minimum of Kabuki syndrome birth incidence was higher, and was calculated at $1: 86,000$ rate [27]. No epidemiological data on prevalence among the Caucasian race is available.

Kabuki syndrome is caused by mutations in KMT2D (formerly, MLL2) or KDM6A genes. KMT2D (locus $12 \mathrm{q} 13.12)$ is responsible for production of $2 \mathrm{D}$ lysinespecific methyltransferase, which is a histone-modifying enzyme. Lysine-specific 2D methyltransferase controls the activity of specific genes, which are crucial for normal development, by attaching the methyl group to histone in the methylation process. KDM6A (locus Xp11.3) also codes the enzyme's protein, i.e., lysine-specific demethylase 6A. It is an important enzyme in the process of histone demethylation, i.e. the separation of the methyl group from some histones. Mutations are inherited in an autosomal dominant pattern or X-linked mode. Approximately, in $30 \%$ of people with Kabuki syndrome, the genetic cause remains unknown $[26,27]$.

Dysmorphic facial features characteristic for Kabuki syndrome include:

- prominent, arched, wide eyebrows, thinning on the sides,

- long palpebral fissures, with an extended lateral part of the lower eyelid (the impression of 'big eyes'),

- epicanthic fold,

- wide nose bridge, flattened, or depressed tip, and short nose column,

- open mouth,

- lip pits (also known as 'lip sinus'), small depressions on the vermilion border or fistulas that penetrate the adjacent minor salivary gland discharging saliva,

- micrognathia, retrognathia,

- strabismus,

- blue sclerae,

- ptosis of the upper eyelid,

- misshaped ears, with protruding, large, 'cup-like' ears $[26,28]$.

Intraoral findings, which are seen in patients with Kabuki syndrome, are as follows: widely spaced teeth, hypodontia, neonatal teeth, misshaped teeth (e.g., screwdriver-shaped crowns of the incisors), delayed teeth eruption, high-arched palate, posterior crossbite, cleft lip/palate, and bifid tongue and uvula [28-30].

Moreover, there are also skeletal abnormalities, fetal pads, mild to moderate intellectual disability, and post-natal growth deficiency (short stature). Additional features of the disease may be presented concerning a variety of internal organs, including heart defects, anus atresia, and urogenital defects. Increased susceptibility to infections, autoimmune and hormonal disorders as well as seizures have also been reported [29].

Usually, individuals with Kabuki syndrome develop speech with delay and present improper language skills, with a need for speech therapy. Articulation errors often occur and are caused by oral-motor hypotonia, poor coordination, and malocclusions. Additionally, patients have abnormal oral resonance, which is caused byhigh-arched palate and oral hypotonia [31,32]. Abnormal oral resonance can be misleading as hypernasality [31].

\section{APERT SYNDROME}

Apert syndrome, also known as 'acrocephalosyndactyly type 1' (ACS-1), is a rare congenital disorder, inherited in an autosomal dominant pattern. It is one of the most severe craniosynostoses. Nowadays, the prevalence is reported to be from $1: 44,000$ to $1: 160,000$ live births, without predilection by gender [33]. 
The main cause of Apert syndrome is a mutation in the FGFR2 gene (fibroblast growth factor receptor-2), locus 10q26.13 [34]. Clinical studies have shown that about $98 \%$ of people diagnosed with Apert syndrome are identified with two mutations, such as Ser252Trp (change of tryptophan into serine at position 252) or Pro253Arg (change of proline into arginine at position 253 ) in the FGFR2 gene [35]. FGFR2 is a protein, which is called 'fibroblast growth factor receptor-2'. That protein is encoded by a gene at locus 10q26. FGFR2 is activated by binding to FGF and participates in a processes, including cell proliferation, differentiation, angiogenesis, wound healing, and embryonic development. FGFR2 protein plays a crucial role in bone growth, especially during embryonic development. Moreover, advanced paternal age has been described as contributing to Apert syndrome (de novo mutations) [36]. That syndrome is characterized by premature cranial suture atrophy, craniofacial hypoplasia, and syndactyly (fusion of fingers and/or toes). Clinical features of Apert syndrome and areas of abnormalities are as follow:

- body growth and development,

- internal organs,

- central nervous system,

- developmental and neuropsychological,

- craniofacial,

- skeletal,

- skin symptoms $[37,38]$.

Among the craniofacial findings are maxillary hypoplasia with third class malocclusion, premature fusion of the $5^{\text {th }}$ and $6^{\text {th }}$ cervical vertebrae, a short, broad nose with a bulbous tip as well as deviated septum, hypertelorism, and flat forehead. Intraoral abnormalities include anterior open bite, bilateral posterior crossbite, narrowing of both tooth arches with crowding, supernumerary teeth, delayed eruption of primary and secondary dentition, hypodontia, enamel hypoplasia, and misshapen incisors [38, 39].

The cleft soft palate and bifid uvula affect $30-76 \%$ of patients [40] and are much more common in patients with Ser252Trp mutation [38]. The soft palate is thick and relatively long [41]. Moreover, a high-arched palate with bilateral swellings of the palatine processes may be misdiagnosed as cleft palate [39]. Among children with Apert syndrome, delayed speech development is often diagnosed. The sounds are nasal. Other defects of the oral cavity result in incomprehensible speech [41].

\section{DIASTROPHIC DYSPLASIA}

Diastrophic dysplasia (diastrophic dwarfism) is a rare form of dwarfism with short limbs and joint malformations, which leads to progressive contractures. Currently, the exact prevalence in general population is unknown [42]. It is estimated that in the United States, diastrophic dysplasia affects about 1 per 500,000 newborns. However, in Finland, this disorder is more common, and occurs in 1 per 330,000 live births [43].

Diastrophic dysplasia is caused by SCL26A2 gene mutation. It is located on the long arm of chromosome 5 (locus 5q32) and codes for a protein responsible for ion transport, especially sulfate ions, through cell membranes that are used to produce proteoglycans, giving cartilage a gum-gel structure. The mutation is inherited in an autosomal recessive manner [43].

The main symptoms of diastrophic dystrophy are short stature, limb shortening, normal size skull, spinal deformities (scoliosis, lumbar hyperlordosis, pelvic kyphosis), contractures of large joints (with deformities and inflammation at an early onset), and so-called 'hitchhiker's thumbs'. Moreover, the standardization of the fingers of the hands, sandal furrow (a gap between the first and second toe), and club foot are observed. Most people with diastrophic dysplasia survive the neonatal period and develop physical limitations, with a normal level of intelligence. It is possible to make a diagnosis in the pre-natal period as well as after childbirth (diagnosis based on clinical symptoms) [42].

Cleft palate is observed in approximately 1 of $3(29 \%)$ cases with diastrophic dysplasia [44]. Speech disorders are associated with a cleft, and include nasal emission, abnormal implementation of $r, s, 1$ sounds, and a hoarse scream [44].

\section{SMITH-LEMLI-OPITZ SYNDROME}

Smith-Lemli-Opitz syndrome (SLOS) is a congenital metabolic disease, inherited in an autosomal recessive manner. Generally, SLOS is diagnosed during the neonatal period. However, the milder form of this disorder can also be detected in adolescence. The cause of SLOS are mutations of DHCR7 gene (locus 11q13.4). In the case of classical and severe forms, the prognosis is unfavorable (severe congenital malformations, stillbirth) $[45,46]$. The incidence of SLOS is estimated between $1: 20,000$ to $1: 40,000$ live births [46].

Smith-Lemli-Opitz syndrome is a syndrome of severe congenital malformations characterized by, among others, disorders:

- craniofacial: microcephaly with narrowing of the frontal region, bowed and low set ears, strabismus, a wide tip of the nose with snapped nostrils, musculoskeletal system,

- limbs: single transverse groove of the hand, Y-shape syndactyly II and III of the toe, short, proximal thumbs, polydactyly of the hands,

- genitourinary system: genital abnormalities (hypospadias, cryptorchidism, micro-penis, etc.) [47].

Muscle tension's disorders are also observed (at first flaccidity, then spasticity). Approximately 50\% of SLOS patients have heart defects, occasional irregularities within the central and peripheral nervous system, and 
organs of vision. Moreover, there is a spectrum of disorders associated with SLOS, including intellectual disability (from moderate to severe) and behavioral disorders (autistic traits in $46-53 \%$ of patients, aggression in $52 \%$, auto-aggression in $35 \%$, obsessive behavior in $52 \%$ of cases). Delayed milestones are noticeable [48].

People with milder forms of Smith-Lemli-Opitz syndrome may only present delicate facial dysmorphisms, muscular hypotension, syndactyly II and III of toes, and mild or no intellectual disability. It is worth noting that clinical differentiation was even noted within one family, because siblings with SLOS were reported with different severity of symptoms and developmental disorders [45]. Facial deformity is characterized by a broad nasal bridge, short nasal root with anteverted nares, and long philtrum. Individuals are identified with malocclusions, such as micrognathia, high-arched, and narrow hard palate with broad alveolar ridges. The redundant sublingual tissues cause disturbances for proper tongue's functioning. CLP is one of the manifestations of SLOS in the stomatognathic system. Moreover, it could appear as a submucous soft cleft palate or bifid uvula [47].

Verbal communication problems may result from disability or autism spectrum disorders [46]. There are no reports in the literature about association of SLOS syndrome with specific speech problems. We might hypothesize that they have to measure themself with making some consonant sounds such as s, $\mathrm{z}$, sh, and nasal sounding. The above-mentioned speech problems are generally caused by CLP and other abnormalities in the oral cavity.

\section{CONCLUSIONS}

The complex nature of cleft palate and/or lips and rare congenital syndromes as the above-mentioned HayWells, Kabuki, Apert, and Smith-Lemli-Opitz syndromes and diastrophic dysplasia. They all require comprehensive management of individuals from birth to maturity. People suffering from incurable diseases, which undoubtedly include genetically determined diseases, must face the problems of self-acceptance and acknowledgement by their peers. Cleft palate is associated with facial deformities and speech difficulties; therefore, patients are often rejected by society, and their quality of life is unsatisfactory. Based on the presented examples of syndromes with CLP, the crucial role of cooperation between pedodontists, orthodontists, speech pathologists, maxillofacial surgeons, and ENT specialists should be emphasized, which can lead to improving quality of life of these patients.

\section{CONFLICT OF INTEREST}

The authors declare no potential conflicts of interest with respect to the research, authorship, and/or publication of this article.

\section{References}

1. Mossey PA, Little J, Munger RG, et al. Cleft lip and palate. Lancet 2009; 374: 1773-1785.

2. Bellis TH, Wolgemuth B. The incidence of cleft lip and palate deformities in the Southeast of Scotland (1971-1990). Brit J Orthodont 1999; 26: 121-125.

3. Vallino-Neapoli LD, Riley MM, Halliday J. An epidemiologic study of isolated cleft lip, palate, or both in Victoria, Australia from 1983-2000. Cleft Palate Cranofac J 2004; 41: 185-194.

4. Kim S, Kim WJ, Oh CC. Cleft lip and palate incidence among the live births in the Republic Korea. J Korean Med Sci 2002; 17: 49-52.

5. Souza J, Raskin S. Clinical and epidemiological study of orofacial clefts. J Pediatr (Rio J) 2013; 89: 137-144.

6. Lei RL, Chen HS, Huang BY, et al. Population-based study of birth prevalence and factors associated with cleft lip and palate in Taiwan 2002-2009. PLoS One 2013; 8: 58690.

7. Eslami N, Majidi MR, Aliakbarian M, Hasanzadeh N. Oral healthrelated quality of life in children with cleft lip and palate. J Craniofac Surg 2013; 24: 340-343.

8. Geneser MG, Allareddy V. Cleft lip and palate. In: Nowak AI, Christensen JR, Mabry TR, et al. (eds.). Pediatric Dentistry. $6^{\text {th }}$ ed. Philadelphia: Elsevier; 2019. pp. 77-87.

9. Jones T, Al-Ghatam R, Atack N, et al. A review of outcome measures used in cleft care. J Orthod 2014; 41: 128-140.

10. Hortis-Dzierzbicka M, Dudkiewicz Z, Stecko E. Psychologiczne aspekty wady rozszczepowej twarzy. In: Hortis-Dzierzbicka M, Stecko E (eds.). Mowa pacjenta z rozszczepem podniebienia. Szkice foniatryczno-logopedyczne. Gdańsk: Wyd. UG; 2005. pp. 119-123.

11. Hunt O, Burden D, Hepper P, et al. Parent reports of the psychosocial functioning of children with cleft lip and/or palate. Cleft Palate Craniofac J 2007; 44: 304-311.

12. Som PM, Naidich TP. Illustrated review of the embryology and development of the facial region, part 1: early face and lateral nasal cavities. AJNR Am J Neuroradiol 2013; 34: 2233-2240.

13. Ansari A, Bordoni B. Embryology, Face [Updated 2019 Jul 22]. In: StatPearls [Internet]. Treasure Island (FL): StatPearls Publishing; 2019 (Accessed: 27.01.2020).

14. Riski JE. Speech, language, and velopharyngeal dysfunction: management throughout the life of an individual with cleft palate. In: Berkowitz S (ed.). Cleft Lip and Palate. Diagnosis and Management. $2^{\text {nd }}$ ed. Germany: Springer; 2005.

15. Kummer AW. Resonance disorders and velopharyngeal dysfunction (VPD). In: Kummer AW (ed.). Cleft Palate and Craniofacial Anomalies - Effects on Speech and Resonance. $2^{\text {nd }}$ ed. New York: Delmar Cengage Learning; 2008.

16. Hunt O, Burden D, Hepper P. Self-reports of psychosocial functioning among children and young adults with cleft lip and palate. Cleft Palate Craniofac J 2006; 43: 598-605.

17. Topolski TD, Edwards TC, Patrick DL. Quality of life: how do adolescents with facial differences compare with other adolescents? Cleft Palate-Craniofac J 2005; 42: 25-32.

18. Oosterkamp BCM, Dijkstra PU, Remmelink HJ, et al. Satisfaction with treatment outcome in bilateral cleft lip and palate patients. Int J Oral Maxillofac Surg 2007; 36: 890-895.

19. Noor SFM, Musa S. Assessment of patients' level of satisfaction with cleft treatment using the cleft evaluation profile. Cleft Palate Craniofac J 2007; 44: 292-303.

20. Sutton VR. Ankyloblepharon-ectodermal defects-cleft lip/palate syndrome.Orphanet;2019.https://www.orpha.net/consor/cgi-bin/ OC_Exp.php?lng=EN\&Expert=1071 (Accessed: 27.01 .2020 ).

21. Westfall MD, Mays DJ, Sniezek JC, Pietenpol JA. The delta Np63 alpha phosphoprotein binds the p21 and 14-3-3 sigma promoters in vivo and has transcriptional repressor activity that is reduced by Hay-Wells syndrome-derived mutations. Mol Cell Biol 2003; 23: 2264-2276.

22. Fete $M$, van Bokhoven $H$, Clements SE, et al. International research symposium on ankyloblepharon-ectodermal defects-cleft 
lip/palate (AEC) syndrome. Am J Med Genet Part A 2009; 149A: 1885-1893.

23. Chopra A, Mitra D, Kandpal R. Rare variant of ankyloblepharonectodermal defect-cleft lip/cleft palate syndrome: curly hair-ankyloblepharon-nail disease syndrome. Int J Trichol 2018; 10: 17-20.

24. Dishop MK, Bree AF, Hicks MJ. Pathologic changes of skin and hair in ankyloblepharon-ectodermal defects-cleft lip/palate (AEC) syndrome. Am J Med Genet Part A 2009; 149A: 1935-1941.

25. Nagaveni NB, Umashankara KV. Hay-Wells syndrome of ectodermal dysplasia: a rare autosomal dominant disorder. Indian J Hum Genet 2011; 17: 245-246.

26. Adam MP, Hudgins L, Hannibal M. Kabuki syndrome. In: Adam MP, Ardinger HH, Pagon RA, et al. (eds.). GeneReviews [Internet]. Seattle: University of Washington; 2011.

27. Porntaveetus T, Abid MF, Theerapanon T, et al. Expanding the orodental and mutational spectra of Kabuki syndrome and expression of KMT2D and KDM6A in human tooth germs. Int J Biol Sci 2018; 14: 381-389.

28. Matsumoto N, Niikawa N. Kabuki make-up syndrome: a review. Am J Med Genet C Semin Med Genet 2003; 117: 57-65.

29. Cudzilo D, Czochrowska E. Orthodontic treatment of a Kabuki syndrome patient. Cleft Palate Craniofac J 2018; 55: 1175-1180.

30. Santos B, Ribeiro R, Stuani A, Paula-Silva F, Queiroz A. Kabuki make-up (Niikawa-Kuroki) syndrome: dental and craniofacial findings in a Brazilian child. Braz Dent J 2006; 17: 249-254.

31. Upton S, Stadter CS, Landis P, Wulfsberg EA. Speech characteristics in the Kabuki syndrome. Am J Med Genet Part A [Internet] 2003; 116A: 338-341. Available from: https://onlinelibrary.wiley. com/doi/abs/10.1002/ajmg.a.10039.

32. Malik P, Sharma A, Sakhuja S, Munjal S, Panda N. Measuring the quality of rural-based, government health care workers in Nepal. IJAHSP 2010; 8: 1-4.

33. Jones KL, Jones MC, Del Campo M. Craniosynostosis syndromes. In: Jones KL (ed.). Smith's Recognizable Patterns of Human Malformation. Philadelphia: Elsevier; 2013. pp. 530-559.

34. Wilkie AOM, Slaney SF, Oldridge M, et al. Apert syndrome results from localized mutations of FGFR2 and is allelic with Crouzon syndrome. Nat Genet 1995; 9: 165-172.

35. Moloney DM, Slaney SF, Oldridge M, et al. Exclusive paternal origin of new mutations in Apert syndrome. Nat Genet 1996; 13: 48-53.

36. Ornitz DM, Marie PJ. Fibroblast growth factor signaling in skeletal development and disease. Genes Dev 2015; 29: 1463-1486.

37. Jakubiuk-Tomaszuk A, Boćkowski L, Sobaniec W. Opis przypadku 15-letniej dziewczynki z zespołem Aperta. Neurologia Dziecięca 2012; 21: 69-72

38. Vadiati Saberi B, Shakoorpour A. Apert syndrome: report of a case with emphasis on oral manifestations. J Dent (Tehran) 2011; 8: 90-95.

39. López-Estudillo AS, Rosales-Bérber MA, Ruiz-Rodríguez S, et al. Dental approach for Apert syndrome in children: a systematic review. Med Oral Patol Oral Cir Bucal 2017; 22: 660-668.

40. Lu X, Sawh-Martinez R, Forte AJ, et al. Classification of subtypes of Apert syndrome, based on the type of vault suture synostosis. Plast Reconstr Surg Glob Open 2019; 7: e2158.

41. Kaloust S, Ishii K, Vargervik K. Dental development in Apert syndrome. Cleft Palate Craniofac J 1997; 34: 117-121.

42. Honório JC, Bruns RF, Gründtner LF, et al. Diastrophic dysplasia: prenatal diagnosis and review of the literature. Sao Paulo Med J 2013; 131: 127-132.

43. Srikanth SR, Telema N, Weili Ch. Diastrophic dysplasia, a rare cause of congenital dwarfism. Ped Neo Bio Open Acc 2016; 1: 000102.

44. Jones KL, Jones MC, Del Campo M. Craniosynostosis syndromes. In: Jones KL (ed.). Smith's recognizable patterns of human malformation. Philadelphia: Elsevier; 2013. pp. 490-492.

45. Nowaczyk M. Smith-Lemli-Opitz syndrome: phenotype, natural history, and epidemiology. Am J Med Genet C Semin Med Genet 2012; 160C: 250-262.

46. Freeman KA, Eagle R, Merkens LS, et al. Challenging behavior in Smith-Lemli-Opitz syndrome: initial test of biobehavioral influences. Cogn Behav Neurol 2013; 26: 23-29.
47. Chen H. Smith-Lemli-Opitz syndrome. In: Chen H. Atlas of Genetic Diagnosis and Counseling. New York: Springer-Verlag; 2017. pp. 2639-2651.

48. Thurm A, Tierney E, Farmer C, et al. Development, behavior, and biomarker characterization of Smith-Lemli-Opitz syndrome: an update. J Neurodev Disord 2016; 8: 12. 